\title{
PRODUÇÃO COLETIVA DE CONHECIMENTOS SOBRE QUALIDADE DE VIDA: POR UMA EDUCAÇÃO AMBIENTAL PARTICIPATIVA E EMANCIPATÓRIA
}

\section{Collective knowledge production on life quality: looking for a critical and emancipated environmental education}

\author{
Nadja Janke ${ }^{1}$ \\ Marília Freitas de Campos Tozoni-Reis ${ }^{2}$
}

\begin{abstract}
Resumo: Unir produção de conhecimentos à ação educativa é a grande responsabilidade da pesquisa em educação ambiental na perspectiva crítica e emancipatória. Percepções e conhecimentos coletivos são essenciais na construção desse novo saber ambiental. Neste artigo, a qualidade de vida é colocada no centro da discussão, mais do que para reivindicar melhorias para o ambiente, mas buscando demonstrar como a participação é seu fundamento e constrói os mecanismos necessários para a ação educativa ambiental.

Palavras-chave: Educação ambiental. Qualidade de vida. Pesquisa-ação-participativa.

Abstract: To connect the production of knowledge to the education is the great concern of the critical and emancipated environmental education. The collective perceptions and knowledge are essential in this construction. In this article, questions of quality of life are placed in the center of the argument that looks, less at the demand for improvements for the environment, and more at the mechanisms of the environmental educative action.
\end{abstract}

Key words: Environmental education. Quality of life. Research-action-participative.

\footnotetext{
${ }^{1}$ Doutoranda, Programa de Pós-Graduação em Educação para a Ciência, Faculdade de Ciências, Unesp, campus de Bauru, SP. <njanke@fc.unesp.br>

${ }^{2}$ Docente, Departamento de Educação do IB-Unesp Botucatu; Programa de Pós-Graduação em Educação para a Ciência, Unesp, campus de Bauru, SP. < mariliaedu@ibb.unesp.br>
}

\footnotetext{
${ }^{1}$ Rua Maria Conceição Zani Alves, 144 Chácara São Marcelo - Mogi Mirim, SP 13.805-050
}

147

Ciência \&̊ Educação, v. 14, n. 1, p. 147-157, 2008 
Janke, N.; Tozoni-Reis, M. F. C.

\section{Introdução}

Como na educação, na educação ambiental há grande diferença entre informar e formar. O processo educativo não se resume a transmitir informações sobre o que fazer para melhorar o ambiente: é preciso investir na formação de sujeitos que concretamente enfrentem a problemática ambiental e comprometam-se com as mudanças necessárias à qualidade de vida no ambiente de forma autônoma e responsável.

A educação ambiental tem, portanto, um caráter formador, que favorece a compreensão e desvela as determinações da realidade humana, de forma a reconstruir em si valores de civilidade e humanidade construídos historicamente. Ou seja, deve instrumentalizar o indivíduo para compreender e agir de forma autônoma sobre sua própria realidade histórica, construída pelas relações sociais. Portanto, a educação ambiental tem como objetivo contribuir para a formação de indivíduos críticos e reflexivos capazes de (re)pensar sua própria prática social.

Isso significa dizer que a construção de uma nova ética é a pauta da educação ambiental (LOUREIRO, 2004). Uma ética que tenha como base a reflexão da complexidade da prática social para, partindo dela, construí-la sob um ponto de vista novo, ecológico no sentido de um "embate democrático entre idéias e projetos que buscam a hegemonia na sociedade e no modo como esta se produz e se reproduz, problematizando valores vistos como absolutos e universais" (LOUREIRO, 2004, p. 51).

A educação ambiental procura, assim, estimular o indivíduo a problematizar suas necessidades reais, buscando, mais que riqueza material, novas relações com os outros, novas formas de tratar a diversidade, empreendendo uma crítica radical à modernidade e valorizando a prática social numa perspectiva ética e ecológica para que o outro e o ambiente sejam parte do sonho de felicidade de todos. Para isto, é necessária uma construção dialógica entre conhecimento sócio-histórico e estético pessoal, construído também pela vivência cultural, ética e social, para imprimir à prática ambiental um caráter contestador, contextualizado e responsável.

Assim, se a educação é mediadora na atividade humana, articulando teoria e prática, a educação ambiental é mediadora da apropriação, pelos sujeitos, das qualidades e capacidades necessárias para à ação transformadora responsável diante do ambiente em que vivem. Podemos dizer que a gênese do processo educativo ambiental é o movimento de fazer-se plenamente humano pela apropriação/ transmissão crítica e transformadora da totalidade histórica e concreta da vida dos homens no ambiente. (TOZONI-REIS, 2004, p. 147)

Nesse sentido, Loureiro (2004) afirma que a educação ambiental tem caráter transformador e emancipatório, desvelando as esferas ideológicas e de alienação, pela possibilidade do diálogo entre diferentes e da construção e compreensão da realidade concreta e sua dinamicidade. 
A realidade ambiental está muito próxima. Basta lembrar que as cidades atuais são grandes centros de degradação, tanto em relação ao ambiente físico quanto social, revelando, escandalosamente, as diferenças sociais. Assim, se o papel da educação ambiental é ajudar a revelar, a si e ao outro, a responsabilidade histórica dos sujeitos para a realização de uma sociedade mais justa e igualitária, sua tarefa é proporcionar condições para que possam interpretar o ambiente em que vivem. Esta interpretação requer muito mais do que conhecimentos sobre condições ambientais favoráveis: tem dimensão subjetiva, no sentido do reconhecimento das necessidades individuais e coletivas, participação e comprometimento com a luta social e emancipatória por um ambiente saudável, que significa melhoria na qualidade de vida.

Há algum tempo a preocupação com a qualidade de vida no planeta, das pessoas e de outros seres vivos, tem se destacado como o objetivo principal a ser alcançado pela atuação ambiental nos diferentes eventos e ações ambientais, nacionais e internacionais. Buscando uma concepção mais aprofundada, entende-se que a qualidade de vida deve ser encarada como realização das condições sociais equilibradas, fortemente influenciada por padrões culturais, sociais, estilos de vida, desejos e aspirações. A construção da qualidade de vida tem a múltipla abrangência necessária para inseri-la no contexto de cada grupo social. Embora com particularidades, algumas condições mínimas são exigidas ao se considerar as necessidades das populações humanas: moradia, educação, saúde, alimentação, entre outros. No entanto, segundo Leff (2001), com o avanço do neoliberalismo, o conceito de qualidade de vida esvaziou-se de compromisso social, sendo considerado muito mais uma reivindicação dos sujeitos para uma vida de privilégios do que dever do Estado na manutenção das necessidades básicas de vida da população. Para camuflar as necessidades reais do conjunto da população, as questões relativas à qualidade de vida vêm sendo tratadas como privilégio de grupos com maior poder de pressão.

$\mathrm{Na}$ sociedade capitalista observam-se valores de acumulação e lucro que, com a massificação - caracterizada pela supervalorização do consumo como promoção da individualidade - desvaloriza o bem estar pessoal e social. Ou seja, a incorporação do estilo consumista da sociedade - compreendido como qualidade de vida - converte em deteriorização do ambiente, subvalorizando, ainda, e em conseqüencia, a qualidade ambiental como forma de bem-estar (LEFF, 2001). Outra conseqüência importante da valorização do consumo como qualidade de vida, segundo esse autor, é a discriminação ou marginalização daqueles que não podem manter os mesmos padrões de consumo. Porém, e ao mesmo tempo, o que se torna acessível a todos é considerado de pouca qualidade, determinando que um padrão positivo de qualidade de vida está na impossibilidade de todos à aquisição material. Isso tem reflexo direto nos padrões de bem estar social básicos, como moradia, alimentação, saúde, educação, entre outros, que, se restritos a aparelhos de Estado na organização neoliberal das sociedades, são mal oferecidos e de pouca qualidade.

De qualquer modo, é impossível identificar padrões para as concepções de qualidade de vida de cada indivíduo, tantos são os fatores que movimentam e orientam as escolhas, os desejos, as vontades e necessidades de cada grupo social. Porém, qualquer estudo que procure trabalhar com a temática da qualidade de vida deve estar amparado por estas concepções e buscar estudá-los dentro das condições de vida de cada grupo social. É importante partir do princípio de que é impossível determinar os indicadores de qualidade de vida de uma comunidade sem a participação, direta e intencional, de quem vivencia tal realidade, trazendo para a 
Janke, N.; Tozoni-Reis, M. F. C.

compreensão desses indicadores as esperanças, os sonhos e as necessidades daqueles que nela vivem e a constroem. É preciso destacar que isso exige buscar uma alternativa metodológica para a investigação desta realidade.

Este artigo apresenta os resultados de um estudo que definiu como metodologia aquela que possibilita a participação radical dos sujeitos na produção dos conhecimentos sobre qualidade de vida no ambiente social e histórico: a pesquisa-ação-participativa. Formulou-se, então, como problema de pesquisa, a "identificação coletiva dos indicadores de qualidade de vida para os moradores de um bairro de periferia da cidade de Bauru-SP para discutir, também coletiva e participativamente, os mecanismos para o enfrentamento dos problemas ambientais da comunidade".

\section{Da produção participativa do conhecimento à ação transformadora: em busca de caminhos metodológicos}

Por sua abordagem qualitativa, a pesquisa-ação-participativa está amparada pelos princípios de compreensão da interpretação humana dos fatos. Porém, possui características próprias que precisam ser compreendidas. Destaca-se a idéia de que esta metodologia objetiva produzir conhecimento sobre o tema a ser estudado, por isso é pesquisa. Porém, a participação efetiva do sujeito diretamente envolvido é fundamental na produção dos conhecimentos sobre sua realidade, uma vez que sua própria observação sobre o ambiente vivido e os problemas que direta e indiretamente o afetam criam conhecimentos que, pela natureza do ambiente produtor desses conhecimentos, devem culminar em ação. Obviamente, participando o sujeito da produção mais elaborada, sistematizada, de conhecimentos sobre sua vida e sua realidade, a ação que esses estimulam é a resposta do processo de conhecimento à realidade de onde emergem.

Se o eixo do processo de produção de conhecimentos sob esta metodologia é a participação, o conhecimento do senso comum surge como ponto de partida, como um "primeiro olhar" sobre a realidade a ser estudada, que carece de reflexão, pois está muito mais relacionado ao viver cotidiano, à experiência do dia-a-dia, que a uma reflexão construída sobre essa experiência. Trata-se, portanto, de desvelar, no processo participativo, o conhecimento de seus condicionantes, das opressões e repressões ocultas, dos valores que determinam tais situações. É então que a vivência dos sujeitos participantes contribui: o senso comum construído a partir das experiências sobre a realidade pode ser ampliado, reconstruído pela realização coletiva de um novo conhecimento, resultado da investigação intensiva e sistematizada sobre essa realidade, sobre as determinações que a constroem, o papel do indivíduo neste processo, o entendimento da responsabilidade de todos. $\mathrm{O}$ avançar desse primeiro olhar, a parceria entre os conhecimentos populares e os conhecimentos do mundo acadêmico, fornece, então, instrumentos à elaboração sistemática para a compreensão mais aprofundada dessa realidade concreta e faz surgir um novo saber: o saber refletido, que compreende os mecanismos históricos, sociais e culturais que determinam a opressão e as condições de vida, realizando a autonomia necessária ao 'fazer', ao agir sobre essa realidade. 
Produção coletiva de conhecimentos sobre qualidade...

A participação possui a característica de ser meio e fim, porquanto é instrumento de autopromoção, mas é igualmente a própria autopromoção. Prevalece, porém, a conotação instrumental, no sentido de que é vista como caminho para se alcançarem objetivos [...]. Se usássemos outra linguagem, diríamos que participação é metodologia [...]. (DEMO, 2001, p. 66)

Por outro lado, a observação sistematizada das questões ambientais por parte dos sujeitos sociais faz com que elas se tornem mais claras e significativas. Destaca-se no processo de investigação um objetivo imprescindível ao trabalho com essa metodologia: seu caráter educativo. Segundo Thiollent (2000), a pesquisa-ação não pode correr o risco de se transformar em ativismo, pois sua intenção é possibilitar o desenvolvimento do "nível de consciência" e do conhecimento dos envolvidos mediante a ação. Portanto, os princípios teórico-metodológicos da pesquisa-ação-participativa aproximam-se dos princípios teórico-metodológicos da educação ambiental.

A primeira etapa de elaboração do projeto de pesquisa-ação-participativa está na formação do grupo de trabalho. Seguem a ela os processos de escolha do tema, do tipo de atuação necessária para agir sobre ele e as formas de tratamento dos resultados obtidos. Estas etapas foram sistematizadas por Angel (2000, p. 50) em: "o desenho da investigação; o desenvolvimento da investigação através de um processo cíclico de planejamento, ação, observação e reflexão; e, por último, a elaboração do informe fina".

Essa metodologia favorece a ação de grupos e movimentos sociais porque prioriza a problematização dos temas pela pesquisa, para dar mais qualidade à ação. Desta maneira, produz novos conhecimentos para os grupos envolvidos, construindo a noção de cidadania de forma consciente e elaborada, possibilitando a ampla estruturação dos princípios da educação ambiental: participação efetiva de toda a comunidade na melhoria do ambiente; articulação entre o conhecimento científico e o senso comum; estruturação da práxis, isto é, busca pela complementaridade entre reflexão e ação; consciência da intencionalidade política da ação ambiental; e garantia da continuidade do processo educativo.

Com estas referências teórico-metodológicas, a proposta deste estudo foi tratar o tema da "qualidade de vida" estabelecendo a articulação radical da produção de conhecimentos e ação educativa comunitária. O tema, pela sua natureza, foi genericamente proposto, de modo a possibilitar que seu detalhamento fosse construído coletivamente. Sua amplitude caracterizou-o sob o ponto de vista da abordagem ambiental, o que significa que a qualidade de vida foi o ponto de partida, tomado como tema gerador da ação investigativa e educativa. Se a qualidade de vida esteve no centro da produção coletiva de conhecimentos, um outro tema relevante para a pesquisa em educação ambiental resultou de todo processo: o potencial dos estudos participativos para o trabalho educativo ambiental. "A pesquisa foi feita pra gente conhecer melhor o que era importante para os moradores. Pra gente poder trabalhar com as necessidades do bairro [...] A gente também tem que fazer a nossa parte, estudar o que precisa ser feito pra poder mudar" (depoimento de um dos pesquisadores comunitários).

Os sujeitos parceiros da pesquisa foram os membros da diretoria da Associação de Moradores do bairro. Mas, durante o desenvolvimento do estudo - principalmente na fase da ação - outros sujeitos foram incorporados: os diretores, professores e alunos da escola esta- 
Janke, N.; Tozoni-Reis, M. F. C.

dual do bairro e um grupo de professores e alunos da Faculdade de Arquitetura da Unesp, campus de Bauru.

\section{Da produção participativa do conhecimento à ação transformadora: compreendendo os resultados}

O auto intitulado GPC - Grupo de Pesquisadores Comunitários - foi formado na primeira fase do processo de pesquisa, quando aconteceram reuniões e discussões sobre as metodologias mais significativas para a investigação dos indicadores de qualidade de vida junto àquela comunidade. Decidiu-se, coletivamente, pela entrevista semi-estruturada. Todos os participantes do grupo entrevistaram moradores do bairro, trazendo dados que permitiram conhecer um pouco de suas satisfações e insatisfações com relação a seu ambiente. $O$ interessante é que, por também residirem no bairro, além de contribuir na organização e realização das entrevistas, na coleta, organização e análise dos dados, pelas discussões realizadas os próprios entrevistadores contribuíram com suas percepções sobre aquele ambiente, problematizando, também, quais seriam as dificuldades mais concretas para trabalhar tais temas naquele espaço social de forma mais produtiva. Isso significa que os participantes do GPC assumiram papéis bastante diversificados no processo de pesquisa e foram, com relação à coleta de dados, entrevistadores e entrevistados. Assim, o trabalho realizado pelo Grupo revelou a todos, de forma refletida, os indicadores de qualidade de vida, conforme segue:

\section{INDICADORES DE QUALIDADE DE VIDA}

BAIRRO BAURU-2000

SAÚDE:

- posto de saúde e pronto socorro: os mais próximos são muito afastados do bairro;

. a saúde não foi tratada por ninguém sob o ponto de vista da prevenção, relacionada ao lixo, à poluição ou à higiene, foi tratada apenas quanto à necessidade de equipamentos públicos para o atendimento em saúde.

\section{EDUCAÇÃO:}

- as escolas do bairro foram consideradas suficientes para a maioria dos entrevistados, porque são próximas e são consideradas por eles como de boa qualidade;

. expressaram a necessidade de uma escola de educação infantil e uma creche para o bairro.

\section{SEGURANÇA:}

. o que causa certa preocupação são as casas abandonadas, que se transformam em local de invasão por pessoas que, segundo os entrevistados, usam drogas;

. a falta de ronda policial também foi indicada, obrigando a contratação de segurança particular que não é muito eficiente. 
Produção coletiva de conhecimentos sobre qualidade...

MORADIA:

. a construção das casas é precária: os cômodos são mal divididos, a estrutura é mal feita, ocasionando problemas como infiltrações, rachaduras nas paredes, e problemas com o esgoto.

LAZER:

- as escolas foram apontadas como o espaço de lazer para as crianças: o Programa Escola da Família, que acontece nos finais de semana, na escola estadual, e a quadra de esportes da escola municipal;

- falta de infra-estrutura de lazer no bairro; a construção de praças pela Prefeitura, em locais já definidos por ela, até hoje não foi concretizada.

\section{ÁREAS VERDES:}

. existem muitas áreas verdes naturais no bairro;

. as áreas verdes estão mal cuidadas e não têm infra-estrutura para o lazer, que seria a função ideal dessas áreas, segundo os moradores entrevistados;

. não existe arborização nas vias e muito menos nas praças.

\section{POLUIÇÃO:}

1) O Córrego Barreirinho - o córrego e suas margens são apontados como um local para o lazer, a diversão; o córrego está poluído; a contaminação da água e o risco de doenças foram considerados; é impossível nadar, pescar e usar a água do córrego para outros fins;

2) Limpeza Pública - o problema com o lixo está no comportamento dos próprios moradores: depositam o lixo nos terrenos baldios, nas vielas, que são locais de passagem, nas casas abandonadas e nas áreas verdes do bairro; a preocupação com o lixo depositado nesses lugares obedece a razões estéticas - nenhum dos entrevistados ressaltou a articulação deste problema com a saúde pública - trata-se de um problema visual.

\section{TRANSPORTE:}

. os ônibus transitam em poucas ruas do bairro, o que significa que quem mora na parte de baixo fica longe dos pontos, portanto tem que subir um longo declive, o que é particularmente ruim para os idosos, e é motivo de atrasos nos compromissos.

\section{VIAS PÚBLICAS:}

. o asfalto é de péssima qualidade; as ruas não têm boca de lobo e a enxurrada das chuvas destrói o asfalto, fazendo grandes buracos;

. algumas ruas estão sem asfalto;

- o bairro não possui ligação com os demais bairros da região: só tem uma saída para carros, o que faz com que o trajeto seja muito longo e tudo fique longe para os moradores.

\section{REDE DE APOIO:}

- a rede de apoio que apareceu nas entrevistas refere-se às relações sociais entre vizinhos, que apóiam ou auxiliam na manutenção da vida dos envolvidos. 
Janke, N.; Tozoni-Reis, M. F. C.

Esses indicadores de qualidade de vida foram organizados pelo Grupo que os classificou, em ordem de importância, em: limpeza pública; qualidade das moradias; lazer e áreas verdes; vias públicas. Pode-se perceber que, identificados entre os moradores entrevistados, caracterizam sua vida nesse ambiente urbano. Olhados de forma tão sistematizada, parecem peças de um quebra-cabeça a ser montado e interpretado. É preciso, no entanto, que sejam compreendidos de forma complexa, pois só assim podem demonstrar muito mais do que a especificidade na qual estão determinados. Isso porque estão intimamente ligados ao modo de viver urbano e dizem respeito - muito mais do que morfologicamente - aos processos sociais, históricos e políticos da organização nas cidades.

Segundo Lefebvre (1991), as cidades sofreram modificações profundas ao longo da história. As cidades pré-industriais, por exemplo, já se diferenciavam dos centros feudais, onde o poder estava contido nas mãos do dono das terras, que investia improdutivamente grande parte de sua riqueza na cidade que dominava. Com o dinheiro e poder passando à mão dos comerciantes, graças ao comércio, ao banco e à usura, as cidades foram se tornando cada vez mais centros de vida social e política, acumulando não apenas riquezas como também conhecimentos, técnicas e obras, como monumentos (LEFEBVRE, 1991). Segundo o autor, lugarejos e aldeias essencialmente agrícolas que mantinham apenas um comércio local foram desaparecendo em função da mudança dos habitantes para os centros urbanos, que passaram a sustentar a agricultura e ofereciam novas oportunidades. A cidade centralizou todo o movimento social e a luta de todas as classes e segmentações sociais pelo direito ao espaço urbano comum.

Com o início da industrialização e a instalação das indústrias muitas vezes fora do ambiente urbano, as cidades tornaram-se o centro econômico, financeiro e comercial da vida social, embora esvaziadas de seu caráter residencial, já que as pessoas se deslocaram para as periferias distantes, residenciais ou próximas aos centros de produção (LEFEBVRE, 1991). Esse movimento fez com que os centros da cidade fossem esquecidos, perdendo-se o caráter da luta daquele espaço como ambiente democrático. Essa perda também aconteceu nas periferias, mas em sentido contrário. Ou seja: houve desfragmentação imediata do modo de vida urbano dos indivíduos, já que então estavam afastados de todos os serviços públicos, como hospitais, escolas, posto de saúde etc... que, na grande maioria, concentravam-se nos centros das cidades (DUPUY, 1980). A mudança para um novo lugar, estranho e incompleto do ponto de vista urbano, descaracterizou, desarticulou as lutas e os movimentos sociais. O indivíduo não se sentia pertencente àquele espaço. Além disso, e aumentando o quadro desfavorável, a emergência pela construção de um grande número de moradias para esses novos habitantes fez com que as necessidades fossem diminuídas enquanto prioridades. Para essa grande expansão, prioridade era moradia, e isso foi feito. Não importava que fossem necessários, também, equipamentos de saúde, educação e lazer, entre outros.

Embora essa análise tenha sido feita para um outro momento histórico, em outra realidade, parece haver grande contemporaneidade nessas constatações. As discussões no Grupo identificaram o ambiente da área periférica da cidade de Bauru como fragmentado, deslocado da vida e da realidade urbana. Qualidade de vida passou a ter, para nós, importância especial: descobrimos que não se trata de trabalhar com as prioridades sociais, mas com as necessidades expressas pelos moradores. O que pudemos observar em muitos bairros dessa mesma natureza, como em muitos conjuntos habitacionais, é que eles são espaços construídos 
Produção coletiva de conhecimentos sobre qualidade...

apenas como prioridade social urbana, não havendo, nas políticas públicas de sua construção, preocupação com as necessidades dos sujeitos concretos relacionadas ao ambiente urbano. Por esse motivo são tão carentes em infra-estrutura. Pudemos perceber, em nosso estudo sobre as necessidades dos sujeitos neste fragmentado ambiente urbano, que essencial não é somente, e apenas, um lugar para morar: é a proximidade a escolas, serviços de saúde, áreas verdes e arborização, estruturas de lazer, entre outros; equipamentos presentes, em grande maioria, apenas nos centros das cidades, ou seja, deslocados do convívio das periferias.

O entendimento dos indicadores de qualidade de vida não apenas em suas características físicas, de falta, mas no que essa falta representa em comprometimento político, ação reivindicatória, planejamento participativo e à própria autopromoção era o interesse deste estudo, caracterizando os indicadores como temas geradores dessa mobilização.

Entendemos por autopromoção a característica de uma política social centrada nos próprios interessados, que passam a autogerir ou pelo menos a co-gerir a satisfação de suas necessidades, com vistas a superar a situação assistencialista de carência e ajuda. Em política social, não se promove ninguém propriamente, caso não chegue a autopromover-se. (DEMO, 2001, p. 67)

Para serem tomados como temas geradores de uma proposta de educação ambiental participativa, os indicadores de qualidade de vida foram compreendidos como conteúdos concretos da luta política pela reforma urbana, da luta pelo direito à cidade.

A relação entre o movimento social pelo direito à cidade e o movimento ambientalista tem registros significativos. O tratado "Por Cidades, Vilas e Povoados Justos, Democráticos e Sustentáveis", pactuado no Fórum Internacional de Reforma Urbana que aconteceu paralelo à Conferência das Nações Unidas sobre o Meio-Ambiente, a Rio-92, debateu desenvolvimento sustentável e reforma urbana, assentamentos, moradia e saneamento básico, cidadania, poder local e qualidade de vida (BENJAMIM, 1993).

Lefebvre (1991) discute que a vida urbana não é um sistema que se impõe aos sujeitos, mas é construída por eles, social e historicamente. Ele afirma que compreender a cidade como "uma projeção da sociedade sobre um local, isto é, não apenas sobre o lugar sensível como também sobre o plano específico, percebido e concebido pelo pensamento que determina a cidade e o urbano" (LEFEBVRE, 1991, p. 56), exige compreendê-la como um todo dinâmico, como "síntese de múltiplas determinações".

A participação popular na construção de uma reforma urbana que tenha a sustentabilidade como fundamento foi debatida por Coelho (1993), que apontou como diretrizes políticas a superação da dominação territorial do espaço urbano, a crítica à lógica dual de cidade - de exclusão social - o direito à vida na cidade, o direito ambiental urbano, a construção de uma esfera pública politicamente ativa e democrática e a dimensão radicalmente pública dos serviços urbanos. A sustentabilidade como fundamento para repensar a vida urbana também foi discutida por Leff (2001), no sentido da construção do saber ambiental, objetivo da educação ambiental.

A construção da proposta de educação ambiental que emergiu dos dados coletados 
Janke, N.; Tozoni-Reis, M. F. C.

pelo Grupo teve, então, a luta pela reforma urbana e a sustentabilidade como eixos de atuação. Entende-se que o processo educativo ambiental, naquele espaço urbano e a partir dos indicadores de qualidade de vida identificados e compreendidos, deveria ser mais do que contribuir para a organização dos moradores para o enfrentamento pontual desses problemas. Os indicadores de qualidade de vida - limpeza pública, qualidade das moradias, lazer e áreas verdes, e vias públicas - deveriam ser tomados como temas geradores de um processo participativo de conscientização das condições de vida das pessoas em busca da realização, plena e transformadora, da sociedade urbana. O direito à cidade foi tratado, naquela comunidade, naquele espaço social, histórico e político, como tema aglutinador de ações educativas ambientais. Ao movimento empreendido pela melhoria da qualidade de vida no bairro, uniram-se novos colaboradores: a comunidade escolar e um grupo de professores e alunos da Unesp campus de Bauru. Juntos, buscamos realizar ações para enfrentamento dos problemas encontrados.

Desta forma, os participantes do Grupo foram incentivados a contar suas experiências aos estudantes, trazendo novos conhecimentos sobre a vida na comunidade, possibilitando fecundas discussões sobre os problemas sócio-ambientais identificados e criando condições objetivas para a mobilização de todos em busca de melhoria na qualidade de vida.

\section{Conclusão}

A investigação sobre os indicadores de qualidade de vida empreendida pelo Grupo de Pesquisadores Comunitários, com referencial teórico, na educação ambiental, de abordagem crítica, transformadora e emancipatória e referencial metodológico na pesquisa-açãoparticipativa, produziu coletivamente conhecimentos significativos sobre a vida da comunidade no ambiente urbano, ao mesmo tempo em que realizou ações educativas ambientais. Os resultados deste processo investigativo foram aqui apresentados e, como conclusão, destacam-se a possibilidade e a importância da parceria entre o conhecimento acadêmico (que emerge da instituição de pesquisa) e o conhecimento comunitário (que emerge da realidade estudada).

O envolvimento da comunidade na formação do Grupo foi significativo e os resultados da pesquisa coletiva, depois de organizados e analisados, foram socializados para os demais membros da comunidade, principalmente pela atuação que aconteceu na escola. Vivenciou-se, neste processo, uma inversão da lógica vigente: ao invés de a escola produzir conhecimentos para a comunidade, foi esta que produziu conhecimentos para a escola. A idéia de levar à comunidade escolar os conhecimentos gerados fora dos tradicionais espaços acadêmicos foi prontamente aceita pela diretoria que viu, ali, a possibilidade de estimular a atuação de professores e alunos na comunidade do entorno, caracterizando uma atuação integrada em busca da melhoria da qualidade de vida na construção, cada vez mais democrática, da participação de todos como ponto fundamental para a criação de sociedades sustentáveis. 
Produção coletiva de conhecimentos sobre qualidade...

\section{Referências}

ÁNGEL, J. L. La investigación-acción: un reto para el profesorado. 2. ed. Barcelona: INDE Publicaciones, 2000.

BENJAMIM, W. Apresentação. In: GRAZIA, G. (Org.). Direito à cidade e meio ambiente. Rio de Janeiro: Fórum Brasileiro de Reforma Urbana, 1993. p. 68-92.

COELHO, F. D. Desenvolvimento sustentado e reforma urbana. In: GRAZIA, G. (Org.) Direito à cidade e meio ambiente. Rio de Janeiro: Fórum Brasileiro de Reforma Urbana, 1993. p. 54-67.

DEMO, P. Política social e participação. In: Participação é conquista. São Paulo: Cortez, 2001. p. 47-82.

DUPUY, J. P. Introdução à crítica da ecologia ambiental. Rio de Janeiro: Civilização Brasileira, 1980.

LEFEBVRE, M. H. O direito à cidade. São Paulo: Moraes Ltda., 1991.

LEFF, E. Saber ambiental: sustentabilidade, racionalidade, complexidade, poder. Rio de Janeiro: Vozes, 2001.

LOUREIRO, C. F. B. Trajetória e fundamentos da educação ambiental. São Paulo: Cortez, 2004.

THIOLLENT, M. Metodologia da pesquisa-ação. 10. ed. São Paulo: Cortez/Autores Associados, 2000.

TOZONI-REIS, M. F. C. Educação ambiental: natureza, razão e história. Campinas: Autores Associados, 2004. 